\title{
Correspondence
}

\section{Distribution of radiocolloids after injection into knee}

Sir,

Williams et al. (1976) have provided useful confirmation of the effectiveness of bed rest in ensuring maximum retention of isotope in a joint, particularly of gold 198.

One sentence in their article is perhaps misleading. It should be clearly understood that in only one of the publications that they quote were some patients not strictly rested in bed (Gumpel et al., 1973). In our single centre comparison of four yttrium 90 colloids (Gumpel et al., 1975) we compared the retention of citrate, ferric hydroxide, resin, and silicate, in randomly selected patients in identical conditions. Although our figures for retention of ferric hydroxide were not grossly different from those given by Williams et al., the variability of retention in the knee in individual patients was much greater with ferric hydroxide than with silicate. This is clearly shown in one figure in this paper and the results that they have quoted from a paper on chromosomal damage (Gumpel and Stevenson, 1975) are only a brief synopsis of that study.
For this reason we chose to use yttrium 90 silicate rathe्य than ferric hydroxide.

J. M. GuMP属

Rheumatic Disease Study Group Northwick Park Hospital, Watford Road Harrow, Middlesex $H A 13 U$

\section{References}

Gumpel, J. M., and Stevenson, A. C. (1975). Chromosoma damage after intra-articular rejection of different colloido of yttrium 90. Rheumatology and Rehabilitation, 14, 7-1Q2

Gumpel, J. M., Williams, E. D., and Glass, H. J. (1973). Usृ of yttrium 90 in persistent synovitis of the knee. I. Retere tion in the knee and spread in the body after injection Annals of the Rheumatic Diseases, 32, 223-226.

Gumpel, J. M., Beer, T. C., Crawley, J. C. W., and Farran. H. E. A. (1975). Yttrium 90 in persistent synovitis of t knee-a single centre comparison. The retention an extra-articular spread of four $\mathbf{9 0 - U}$ radiocolloids. British Journal of Radiology, 48, 377-381.

Williams, E. D., Caughey, D. E., Hurley, P. J., and Johñ M. B. (1976). Distribution of yttrium 90 ferric hydroxide colloid and gold 198 colloid after injection into knee Annals of the Rheumatic Diseases, 35, 516-520. 